\title{
INFLUÊNCIA DA CARCINICULTURA SOBRE A SALINIZAÇÃO DO SOLO EM ÁREAS DO MUNICÍPIO DE GUAMARÉ/RN.
}

\author{
Douglisnilson de Morais Ferreira \\ Pesquisador do CEFET/RN, Bacharel em Química - UFRN, vinculado ao grupo de \\ pesquisa em Análise de Águas do CEFET/RN. \\ douglisnilson@cefetrn.br. \\ Jailson Vieira de Melo \\ Professor Adjunto da UFRN, Doutor em Química - UFPE. \\ javiebrazil21@gmail.com. \\ Leão Xavier da Costa Neto \\ Professor Adjunto do CEFET/RN, Doutorando em geologia - UFRN, vinculado ao grupo \\ de pesquisa em Análise de Águas do CEFET/RN. \\ leaoneto@cefetrn.br.
}

\section{RESUMO}

O município de Guamaré está localizado no litoral norte do Rio Grande do Norte, na microrregião de Macau, com uma área territorial de $259 \mathrm{~km}^{2}$ e população de aproximadamente 9700 habitantes (IBGE, 2006). Apresenta acentuada instabilidade morfológica ocasionada, principalmente, pela influência de atividades antrópicas como a carcinicultura e salineira. Essas atividades vêm gerando hipersalinidade residual do solo e da água, fator pelo qual, atualmente, praticamente toda a água dos mananciais da cidade está imprópria para o consumo humano. Vale ressaltar que, essa água, durante muitas décadas, era utilizada pelos moradores da região para a agricultura, pecuária, consumo humano e áreas afins. Além disso, algumas das áreas do município, antes utilizadas em atividades agrícolas, vêm se tornando desertas com elevada mortalidade de árvores de grande porte. A região em estudo tem características de estuário, porém com pequena influência de água doce durante o período chuvoso. Em 2007 foram iniciados estudos para avaliação dos índices de sais existentes nos mananciais da região. Foram selecionados 18 pontos de amostragem coletados de poços, cacimbas, rio (Miassaba), salina e viveiro de camarão e as análises foram executadas pelo Núcleo de Análises de Águas, Alimentos e Efluentes do CEFET/RN.

PALAVRAS-CHAVE: Água, salinidade, carcinicultura, análises, meio-ambiente. 


\section{INFLUÊNCIA DA CARCINICULTURA SOBRE A SALINIZAÇÃO DO SOLO EM ÁREAS DO MUNICÍPIO DE GUAMARÉ/RN.}

\section{INTRODUÇÃO}

A água é um recurso natural que compõe o patrimônio ambiental que deve ser protegido, tendo em vista seu uso coletivo (DUARTE, 1999 apud VIEIRA, 1994). O mau uso das águas, bem como o despejo de resíduos líquidos e sólidos em rios, lagos e represas, falta de saneamento básico e a salinização do lençol freático, vem acarretando a degradação dos recursos hídricos disponíveis e a sua escassez.

A carcinicultura, atividade que visa a criação racional de camarões em cativeiro, é uma das atividades de grandes impactos ambientais, sendo alvo de estudos e discussões entre empresários e ambientalistas. Seu desenvolvimento tem se intensificado, principalmente no nordeste brasileiro, em função da alta rentabilidade econômica, produtividade elevada e adaptação fácil. A região Nordeste é responsável por 94\% da produção nacional, tendo o $\mathrm{RN}$ como um dos principais estados produtores.

Ao atingir o meio ambiente, a carcinicultura ameaça a fonte de sobrevivência e a cultura de milhares de pessoas que habitam tradicionalmente as regiões de mangue, em especial, pescadores e pequenos agricultores.

O crescimento da carcinicultura no Nordeste, a par dos índices econômicos divulgados pelos produtores, vem sendo associado à destruição de um dos ecossistemas mais complexos do planeta, o manguezal, além de atingir mata ciliar e carnaubais e causar danos cumulativos às bacias hidrográficas onde se inserem.

De acordo com o IBAMA/RN, o RN possui mais de 10.000 hectares de viveiros de camarão em todo o Estado, tendo a cidade de Guamaré como uma das grandes produtoras de camarão. A L. vannamei é a espécie cultivada nacionalmente, devido á sua fácil adaptação a águas doces a salinas.

A necessidade de realizar este estudo surgiu pela observação feita na área em que se desenvolve a atividade salineira e da carcinicultura no município, diagnosticando, a partir da entrada da cidade, uma grande extensão de terra em que plantas nativas estão morrendo Outra situação perceptível nesta área é o aumento da salinidade residual da água, aumentando a degradação do meio ambiente.

Esta situação pode ser observada em regiões próximas de viveiros. Segundo moradores da região, a mortandade da vegetação e a hipersalinidade foram observadas após a implantação desses viveiros (Fig. 01). 


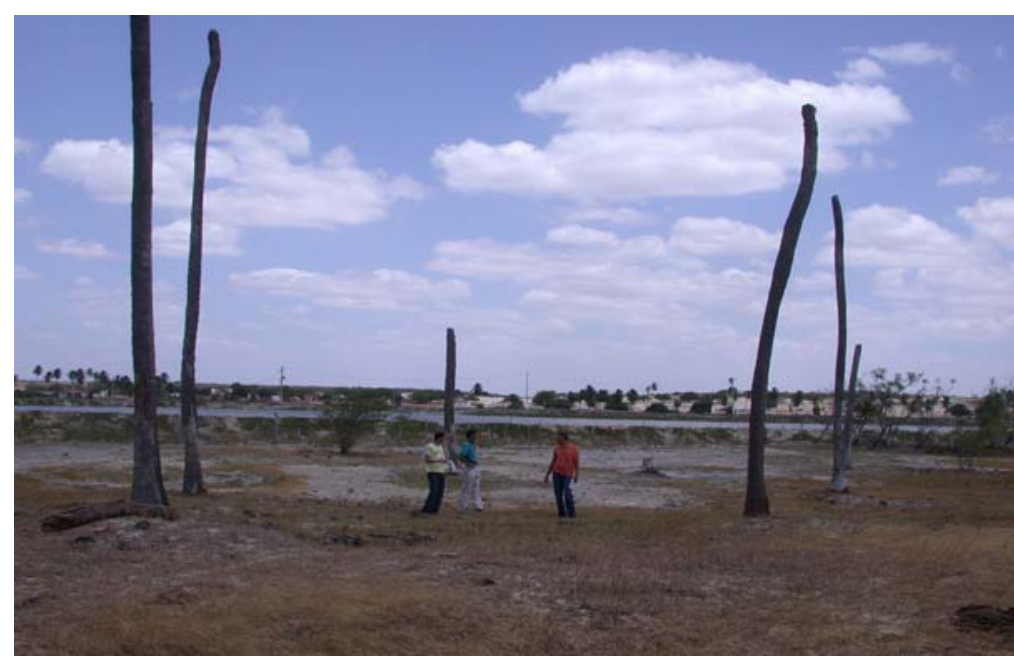

Figura 01 - Imagem atual da vegetação local do município de Guamaré/RN nas proximidades dos viveiros de camarão.

Pensando nesta problemática, este trabalho foi elaborado visando um aprofundamento no estudo da salinidade local e sua relação com as mudanças ocorridas na vegetação nativa da região próxima aos viveiros, buscando alternativas mitigadoras para conter o avanço dessa contaminação, bem como soluções para a reutilização e reaproveitamento dos recursos hídricos locais.

\section{A ÁGUA NA NATUREZA E SEUS IMPACTOS AMBIENTAIS}

A água é um recurso natural renovável indispensável à sobrevivência humana, ao desenvolvimento tecnológico, social e econômico de uma nação. Sua história sobre o planeta terra, sua qualidade e quantidade disponível para uso está relacionada diretamente ao crescimento populacional, desenvolvimento urbanístico e às diversas áreas de atuação (abastecimento público, agricultura, aqüicultura, indústrias, etc.).

Na natureza, ela é encontrada principalmente no estado líquido e cobre aproximadamente $70 \%$ da superfície do planeta. Do total de água doce existente apenas $0,147 \%$ encontra-se disponível na forma liquida para exploração econômica e tecnológica, sendo que desse total $70 \%$ é destinada à agricultura, $22 \%$ à indústria e $8 \%$ ao consumo humano. (MACÊDO, 2005 apud RAINHO, 1999; GALETI, 1983).

Atualmente existem inúmeros problemas de impactos ambientais causados pelas diversas atividades humanas que altera a qualidade da água e seu ciclo hidrológico, gerando sua escassez e aumento no custo. A eutrofização, a contaminação das águas superficiais e subterrâneas e a perda da diversidade biológica são conseqüências destas práticas humanas.

Uma das atividades em constante crescimento no nordeste brasileiro, causadora de inúmeros impactos ambientais é a carcinicultura, que visa a criação racional de camarões em cativeiro. De acordo com a Associação Brasileira dos Criadores de Camarão - ABCC, o nordeste é responsável por 94\% de todo o camarão produzido no Brasil. Entre os maiores produtores estão o Rio Grande do Norte e a Bahia, seguido do Ceará, Paraíba, Pernambuco e Piauí. 
Seu desenvolvimento no Brasil, em especial no Nordeste, é resultado de uma demanda crescente do mercado internacional por camarão cultivado bem como da facilidade de adaptação da espécie L. vannamei a águas desde doce até salinidades mais elevadas. Por outro lado, o crescimento desta atividade, a par dos índices econômicos divulgados pelos produtores, vem sendo associado à destruição de um dos ecossistemas mais complexos do planeta, o manguezal, além de atingir mata ciliar e carnaubais e causar danos cumulativos às bacias hidrográficas onde se inserem.

A Resolução CONAMA n. ${ }^{\circ}$ 312/2002, destaca alguns possíveis impactos que podem ser causados pela implantação de fazendas de camarão, tais como, a degradação do ecossistema e da paisagem, perda da cobertura vegetal, redução da capacidade assimilativa de impactos futuros, redução de áreas propícias à presença de espécies em extinção, alteração da função de filtro biológico, alterações físico-químicas e biológicas de corpos receptores de efluentes, impactos sobre o aqüífero e conseqüente aumento da cunha salina (hipersalinidade).

A carcinicultura, como as demais atividades produtivas, provoca alterações no meio ambiente. São inúmeros os impactos ambientais causados, desde contaminação dos recursos hídricos naturais, através do lançamento de matéria orgânica produzida ao longo de todo o processo de despesca, destruição de manguezais e vegetação nativa e, no caso em questão, a salinização do solo e, consequentemente da água nas áreas próximas às fazendas de camarão.

A salinização afeta diretamente os constituintes naturais do solo e da água. Na água o aumento do teor de sais dissolvidos pode causar restrições nas atividades agrícolas, podendo torná-la imprópria nas condições de condutividade elétrica acima de $3000 \mu \mathrm{S} / \mathrm{cm}$ (COSTA, 2001 apud FRENKEL,1984 e PIZARRO, 1985). Para o consumo humano o teor de sais dissolvidos (TDS) deve ser inferior a $1000 \mathrm{mg} / \mathrm{L}$ e a concentração de cloretos máxima deve ser 250 mg/L (Portaria 518/2004).

Em relação ao solo a salinização além de prejudicar as atividades agrícolas, pode causar a degradação do ecossistema e da paisagem e diminuição da cobertura vegetal. Essa degradação ocasiona a desertificação da área atingida, decorrente da mortalidade de vegetações rasteiras e espécies arbóreas típicas da região (coqueiros, cajueiros, mangueiras, etc.).

Araújo (2007) destaca, em pesquisas desenvolvidas no estuário do rio Acaraú - CE, que implantação de empreendimentos de carcinicultura ao mesmo tempo em que aumenta a economia interna e gera produção de empregos, causa, dentre outros fatores, o desmatamento do manguezal, do apicum e salgado. Costa (2001) apresenta um diagnóstico da influência da salinização do solo nos processos agrícolas na região de Afonso Bezerra/RN.

Partindo dos pontos acima mencionados, surgiu a necessidade de desenvolver a pesquisa no município de Guamaré visando diagnosticar as possíveis causas da salinização do solo e lençol freático da região próxima aos viveiros de camarão, bem como fazer um paralelo da atual situação vegetativa da região com a observada há alguns anos atrás, antes do início da atividade em questão. 


\section{DESCRIÇÃO DA ÁREA DE ESTUDO:}

O município de Guamaré/RN, localizado no litoral norte do RN, microrregião de Macau será o objeto de estudo da pesquisa.

Inicialmente foram selecionados 18 pontos de amostragens como poços artesianos, cacimbas, rio (Miassaba, fig. 02), salina e viveiros de camarão (fig. 03). A figura 04 apresenta o mapa descritivo com a localização georeferenciada dos pontos selecionados para a execução da pesquisa.

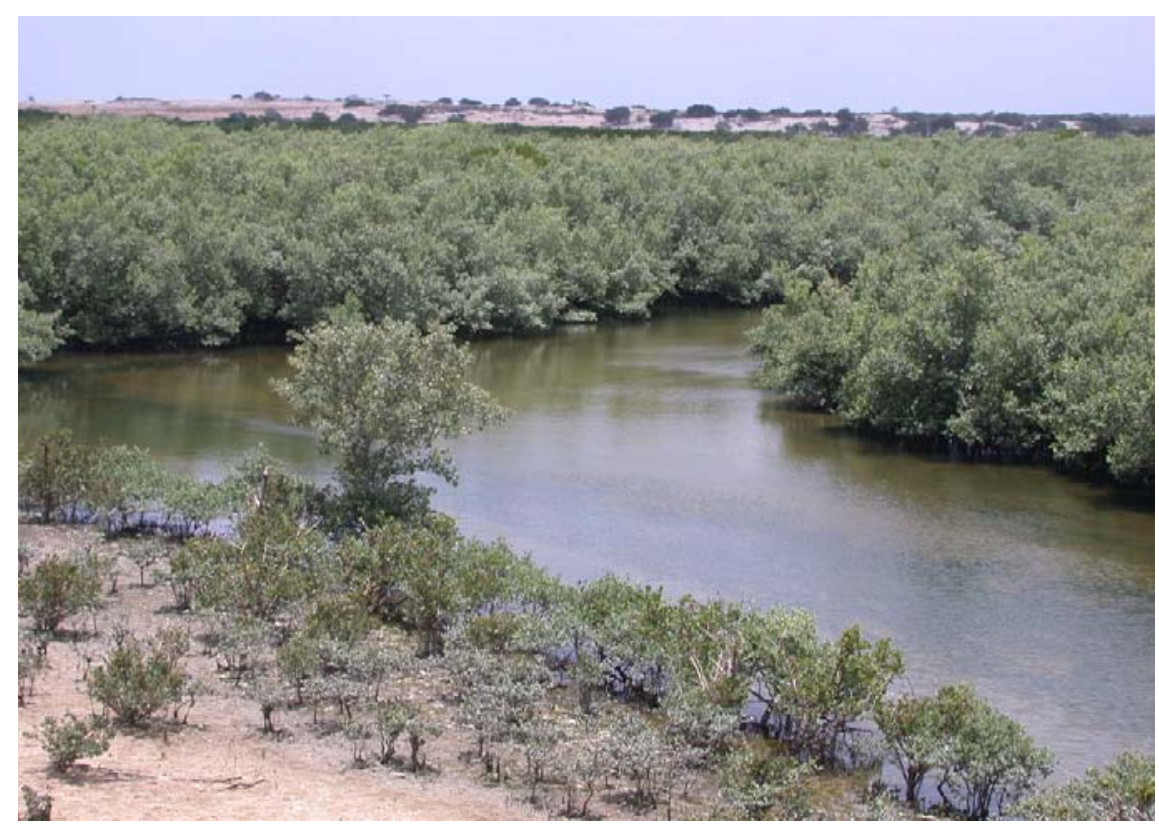

Figura 02 - Imagem do Rio Miassaba - Guamaré/RN.

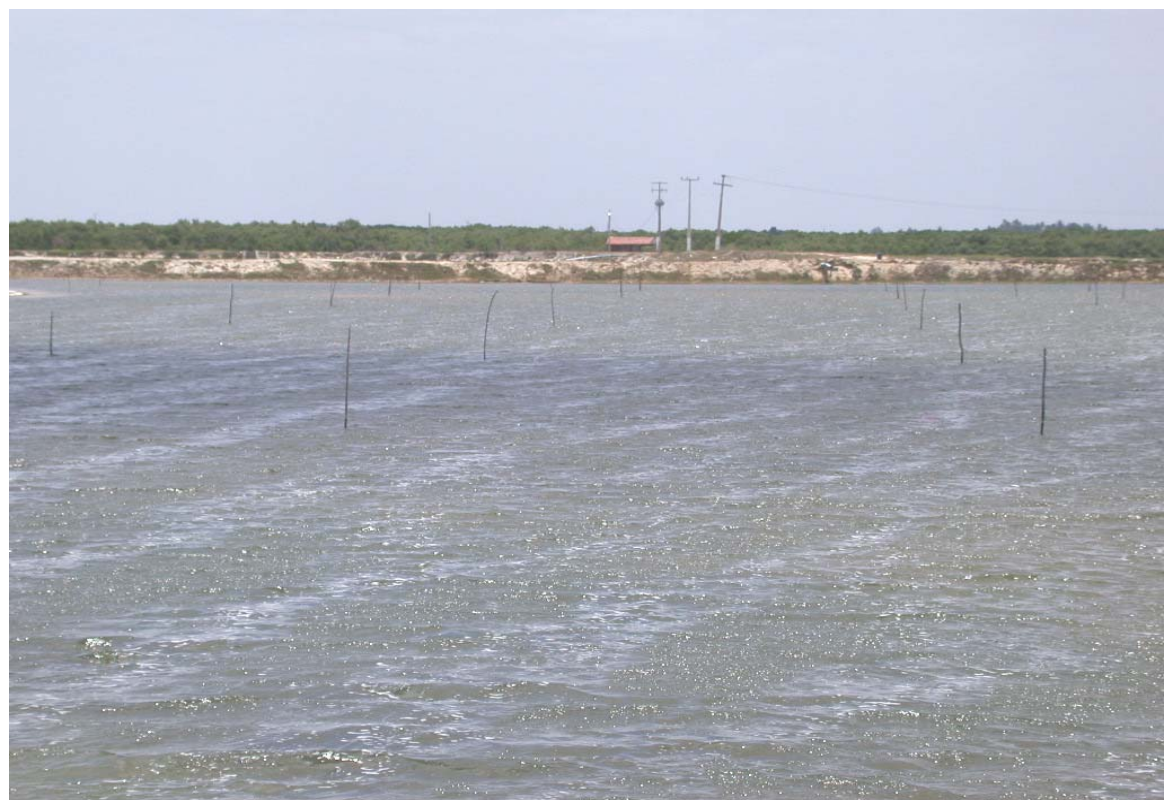

Figura 03 - Imagem dos viveiros de camarão em atividades no município de Guamaré/RN. 


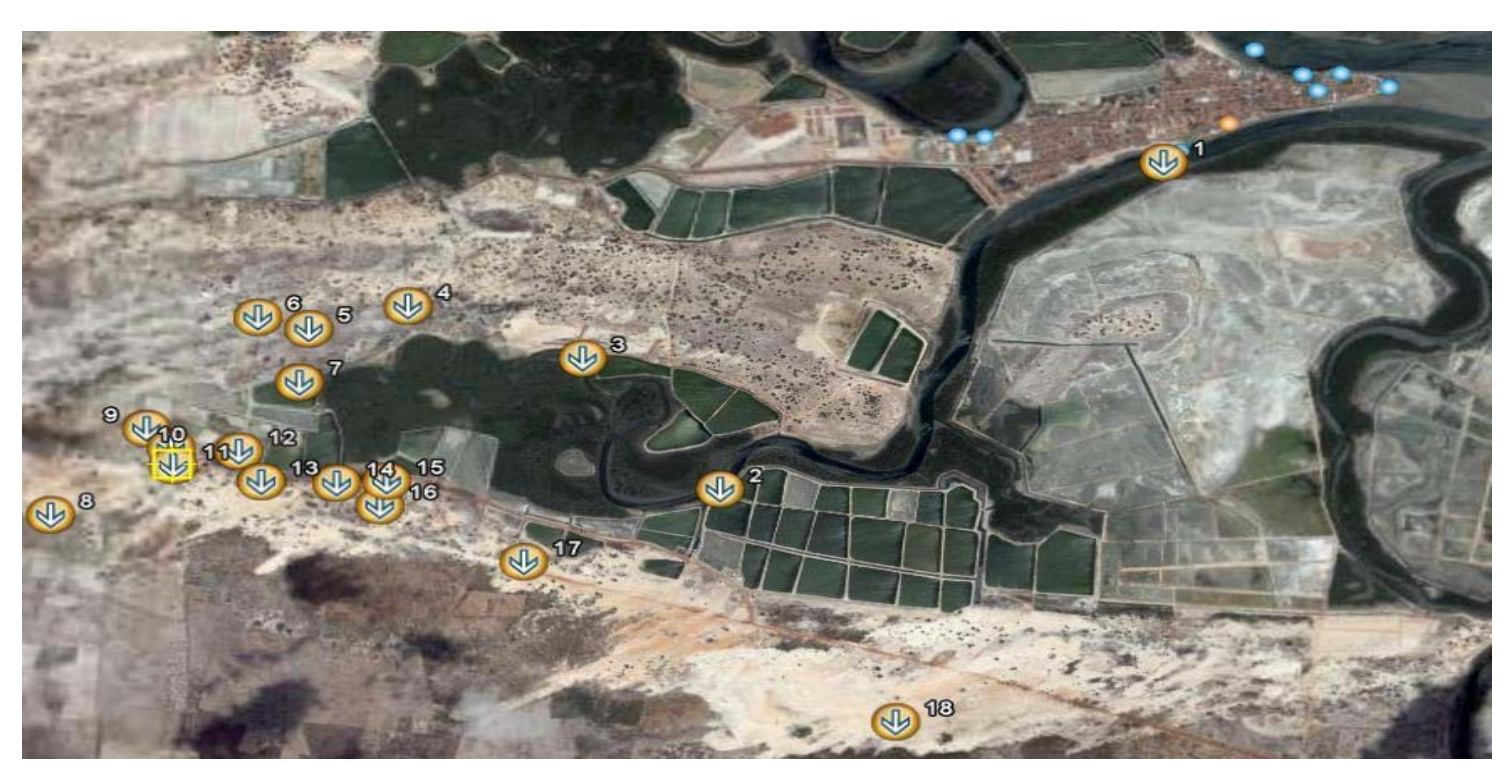

Figura 04: Localização dos pontos de coleta monitorados - Guamaré/RN.

Os 18 pontos selecionados são, respectivamente: Ponte (Guamaré), Rio MIassaba, Canto (Rio), Poço (João Batista), Poço (C. Pedro), CAC (Justino), Viveiro, Cacimba (Padre), Lagoa (J. Antônio), Cacimba (Gado), Lagoa (Sr. Cecílio), Salina, Poço (Sr. José Pequeno), Poço (Pirrita), Poço (Sr. Bil), Cacimba (Sr. Bil), Cacimba (Galego), Cacimba (Dunas).

\section{METODOLOGIA DE COLETA E ANÁLISES}

Os procedimentos de coleta, preservação e armazenamento das amostras de águas adotados são baseados nas recomendações do Standard Methods for The Examination of Water and Wastewater (APHA, 1998). O período de amostragem foi de outubro de 2007 a Janeiro de 2008, sendo realizadas duas campanhas de coleta.

As análises foram realizadas pelo Núcleo de Análises de Águas, Alimentos e Efluentes do CEFET/RN.

Os parâmetros selecionados para as análises de águas do objeto de estudo em questão foram condutividade elétrica, salinidade, $\mathrm{pH}$ e cloretos. As metodologias de análises de águas empregadas são baseadas no Standard Methods for The Examination of Water and Wastewater (APHA, 1998).

\section{RESULTADOS E DISCUSSÕES}

A tabela 01 apresenta um resumo descritivo das concentrações médias dos parâmetros analisados. 
Tabela 01: Resultados das análises obtidos nas coletas de água no município de Guamaré - Outubro/2007 e Janeiro/2008.

\begin{tabular}{|c|c|c|c|c|c|c|c|c|}
\hline \multirow[b]{2}{*}{$\begin{array}{c}\text { PONTOS DE } \\
\text { AMOSTRAGEM }\end{array}$} & \multicolumn{8}{|c|}{ PARÂMETROS ANALISADOS ( $1^{\mathrm{a}}$ e $2^{\mathrm{a}}$ coletas) } \\
\hline & \multicolumn{2}{|c|}{$\begin{array}{l}\text { Condutividade } \\
\text { Elétrica (ms/cm) }\end{array}$} & \multicolumn{2}{|c|}{$\begin{array}{l}\text { Salinidade } \\
\text { (g/L) }\end{array}$} & \multicolumn{2}{|c|}{ pH } & \multicolumn{2}{|c|}{$\begin{array}{l}\text { Cloretos } \\
\text { (g/L) }\end{array}$} \\
\hline $\begin{array}{lcc}01 & \text { - } & \text { Ponte } \\
\text { (Guamaré) } & \end{array}$ & 54,1 & 61,2 & 34,9 & 37,6 & 8,21 & 7,97 & 21,05 & 24,57 \\
\hline 02 - Rio Miassaba & $\mathrm{X}$ & 69,99 & $\mathrm{X}$ & 42,5 & $\mathrm{X}$ & 7,64 & $\mathrm{X}$ & 27,42 \\
\hline 03 - Canto (Rio) & 61,2 & 75,4 & 40,8 & 46,7 & 7,97 & 7,28 & 27,75 & 29,49 \\
\hline $\begin{array}{llll}04- & \text { Poço } & \text { (J. } \\
\text { Batista) }\end{array}$ & 4,4 & 7,48 & 2,4 & 3,7 & 8,27 & 7,55 & 1,44 & 2,22 \\
\hline $\begin{array}{llll}05-\text { Poço } & \text { (C. } \\
\text { Pedro) } & & \\
\end{array}$ & 9,30 & 11,68 & 5,1 & 5,9 & 8,00 & 7,70 & 3,35 & 3,59 \\
\hline 06 - CAC (Justino) & $\mathrm{X}$ & 6,89 & $\mathrm{X}$ & 3,4 & $\mathrm{X}$ & 7,73 & $\mathrm{X}$ & 2,02 \\
\hline 07 - Viveiro & 82,10 & 90,75 & 56,4 & 58,1 & 8,37 & 8,03 & 28,31 & 38,28 \\
\hline $\begin{array}{ll}08- & \text { Cacimba } \\
\text { (Padre) } & \end{array}$ & 0,16 & 0,21 & 0,1 & 0,1 & 7,06 & 6,94 & 0,058 & 0,023 \\
\hline $\begin{array}{l}09-\text { Lagoa (J. } \\
\text { Antônio) }\end{array}$ & $\mathrm{X}$ & 183,46 & $\mathrm{X}$ & 99,1 & $\mathrm{X}$ & 7,67 & $\mathrm{X}$ & 93,12 \\
\hline $\begin{array}{l}10 \text { - Cacimba } \\
\text { (Gado) }\end{array}$ & 35,90 & 49,06 & 22,5 & 29,3 & 9,05 & 7,13 & 16,11 & 16,76 \\
\hline $\begin{array}{l}11-\text { Lagoa (Sr. } \\
\text { Cecílio) }\end{array}$ & 14,40 & 30,13 & 8,30 & 17,5 & 9,54 & 6,92 & 5,61 & 9,83 \\
\hline 12 - Salina & 172,00 & 183,89 & 94,6 & 101,1 & 7,21 & 7,54 & 57,33 & 102,28 \\
\hline $\begin{array}{l}13 \text { - Poço (Sr. José } \\
\text { Pequeno) }\end{array}$ & 3,63 & 3,73 & 1,80 & 1,8 & 8,33 & 7,80 & 1,51 & 1,08 \\
\hline 14 - Poço (Pirrita) & 16,65 & 23,45 & 9,7 & 13,1 & 8,40 & 7,19 & 6,66 & 7,76 \\
\hline 15 - Poço (Sr. Bil) & 73,00 & 90,06 & 48,2 & 59,0 & 8,40 & 8,19 & 28,08 & 38,28 \\
\hline $\begin{array}{l}16 \text { - Cacimba (Sr. } \\
\text { Bil) }\end{array}$ & 18,85 & 22,92 & 10,9 & 12,7 & 8,36 & 7,13 & 6,50 & 7,03 \\
\hline $\begin{array}{lll}17 & - & \text { Cacimba } \\
\text { (Galego) } & \end{array}$ & 6,80 & 20,80 & 3,1 & 11,0 & 8,96 & 7,61 & 2,83 & 6,21 \\
\hline $\begin{array}{lll}18- & \text { Cacimba } \\
\text { (Dunas) } & \end{array}$ & X & 0,36 & X & 0,2 & X & 6,66 & $\mathrm{X}$ & 0,041 \\
\hline
\end{tabular}

Os valores de condutividade variaram de 0,16 $\mathrm{g} / \mathrm{L}$ (Cacimba do padre) até aproximadamente $184 \mathrm{~g} / \mathrm{L}$ (Lagoa J. Antonio, salina); os valores de salinidade variaram desde $0,10 \mathrm{ppt}$ até $101,1 \mathrm{ppt}$. O potencial hidrogeniônico $(\mathrm{pH})$ apresentou variação entre 6,66 e 9,54 e os teores de cloreto variaram de $0,023 \mathrm{~g} / \mathrm{L}$ a $102.28 \mathrm{~g} / \mathrm{L}$.

\section{CONCLUSÕES}

A partir da interpretação dos resultados obtidos pode-se concluir que, apesar de ser considerado como estuário, o canal de maré que compõe o Rio Miassaba se comporta como um estuário invertido, onde a salinidade cresce com o aumento da distância em relação ao mar. Estes resultados podem ser verificados na seqüência dos pontos 01, 02 e 03.

Os pontos 08 e 18 ambos localizados distantes dos viveiros e no alto de dunas foram os únicos em que se encontrou água potável. Em torno do ponto 09 observou-se a mortandade de toda vegetação, porém, este local foi utilizado para retirada de areia para construção, restando ali uma lagoa no mesmo nível do mar e com elevada salinidade como pode ser visto nos resultados. 
Comparando-se os pontos 13 e 15 pode-se observar que o primeiro, com menor índice de salinidade, está separado pelo viveiro por uma vala de drenagem profunda que evita o avanço da salinidade, enquanto que o segundo se encontra próximo ao viveiro sem esta separação.

Os pontos 04, 05 e 06 mostram que quanto mais próximo ao viveiro maior o teor de salinidade. Vale salientar que a água do ponto 05 foi usada durante décadas como potável, principalmente para animais.

O aumento da salinidade do solo em torno do ponto 07 o tornou impróprio para agricultura, causando a morte de todas as árvores, nativas e agricultáveis, como coqueiros, cajueiros, quixabeiras e outras, todas com mais de três décadas de idade. Neste local, a única vegetação que ainda cresce é algum tipo de arbusto típico de ambiente muito salino.

\section{BIBLIOGRAFIA:}

ABCC. Histórico da carcinicultura no Brasil. http://www.abccam.com.br>. Acesso em: 12 de fev. 2008.

AMERICAN PUBLIC HEALTH ASSOCIATION (APHA). Standard methods for the examination of water and wastewater. 20 $0^{\text {th }}$ ed., Washington. APHA, 1998.

ARAÚJO, M.V. Análise dos impactos ambientais causados em estuários: estudo do estuário do rio Acaraú, Ceará - Brasil. . <http://www.ig.ufu.br/revista/caminhos.html>. Acesso em: 13 de fev. 2008.

BRAGA, Benedito et all. Introdução à engenharia ambiental. $2^{\mathrm{a}}$ ed. São Paulo: Pearson prentice hall. 2005. 318p.

COSTA, D. M. A. Caracterização Físico-Química de Solos da Bacia do Rio Cabugi no Município de Afonso Bezerra-RN. 2001. 138 f. Dissertação (Mestrado em Geociências) Centro de Ciências Exatas e da Terra - Universidade Federal do Rio Grande do Norte, Natal, 2001.

DUARTE, M. A. C. Utilização dos índices do estado trófico (IET) e de qualidade da água (IQA) na caracterização limnológica e sanitária das lagoas de Bonfim, Extremoz e Jiqui - RN. 1999. 159 f. Dissertação (Mestrado em Engenharia Civil) - Centro de Ciências e Tecnologia - Campus II, Universidade Federal da Paraíba, João Pessoa, 1999.

IBGE. Dados estatísticos do município de Guamaré/RN. <http://www.ibge.gov.br>. Acesso em: 28 de jan. 2008.

MACÊDO, J. A. B. de. Águas e águas 3 ed. CRQ. Belo Horizonte - MG. 2004. 977p.

MMA - Ministério do Meio Ambiente. Resolução CONAMA No. 312, de 10 de outubro de 2002.

MMA/BID. PNRH: Síntese executiva. Brasília, 2006. 1 CD-ROM. BASES de dados em recursos hídricos. Brasília: MMA/BID, 2006. 1 CD-ROM.

Portaria N N . 518, de 25 de março de 2004.

<http://www.anvisa.gov.br/legis/resol/2004/518>. Acesso em: 13 fev. 2008. 
ROCHA, J. C. et all. Introdução à química ambiental. Porto alegre: Bookman. 2004.

SILVA, Fábio César da. Manual de análises químicas de solos, plantas e fertilizantes. Brasília: EMBRAPA, 1999. 370p.

TUCCI, C. E. M et all. A gestão da água no Brasil: uma primeira avaliação da situação atual e das perspectivas para 2025. São Paulo. 2000. 145p.

TUNDISI, José Galizia. Água no Século XXI: Enfrentando a escassez. São Paulo: Rima, 2003. 